\title{
Illicit Drugs among Crashed Drivers, A First Toxicological Investigation in Albania
}

\author{
Linda Matua ${ }^{1,2}$, Bledar Xhemali ${ }^{1}$, Mirnela Koçibelli ${ }^{1}$, Besnik Jucja ${ }^{2}$ and Gentian Vyshka ${ }^{3 *}$ \\ ${ }^{1}$ Institute of Forensic Medicine, Tirana, Albania \\ ${ }^{2}$ Faculty of Pharmacy, University of Medicine, Tirana, Albania \\ ${ }^{3}$ Faculty of Medicine, University of Medicine, Tirana, Albania
}

\begin{abstract}
This study aims to investigate the presence of drugs in this group of drivers who already had a crash (injured or killed drivers). By law, the prosecutor is the authority who requests the toxicological examination specifying the type of analysis that will be performed, usually only alcohol test is required. There has been some investigation regarding the influence of alcohol in traffic crashes in Albania (3,190,089 inhabitants), but never a research regarding the use of illicit and medicinal drugs in drivers in our country. Alcohol was analyzed in blood by head-space gaschromatography. Blood samples were also screened for psychoactive substances (opiates, cocaine metabolites, cannabis, amphetamines, methamphetamines, benzodiazepines, tricyclic antidepressants, barbiturates) by immunological methods. Their presence was confirmed by gas-chromatography.
\end{abstract}

Overall, 82 car drivers were included in the study. Drivers involved in accidents were more frequently men $98.8 \%$ $(n=81) .46$ drivers $(56.1 \%)$ had a positive blood alcohol concentration at the time of the crash, but only $23(28 \%)$ had toxic concentrations exceeding $1.2 \mathrm{~g} / \mathrm{l}$. In total, $15.9 \%$ were positive for illicit drugs and medicinal drugs. This study revealed that beside alcohol, psychoactive substances were present in Albanian crashed drivers, too.

Keywords: Albania; Drugged driving; Toxicological investigation

\section{Introduction}

The effects of alcohol consumption on safety behavior of drivers have been reported in different studies [1-4]. But, research had shown that illicit drugs and psychoactive medicinal drugs may increase the risk of traffic accidents [5-11]. Driving under the influence is considered as one of the main causes of road crashes, it is a continuous concern for road safety. The most important research projects carried out in the EU aimed to quantify the size of the drink- and drug driving problem in Europe; it was shown that the injured or killed drivers, the most commonly consumed substance was alcohol alone, followed by alcohol combined with other substances [12,13]. Similar investigation took place in different European countries and a number of studies on drink and drug driving were published [14-20]. Regarding Albania, alcohol investigations are performed in crashed drivers $[21,22]$ but it is never investigated about the use of drugs of abuse among drivers involved in road crashes.

According to Republic of Albania 's law on Road Traffic Safety (2011 amendment), it is prohibited driving after drinking or consuming illicit drugs and psychoactive substances. The sanctions for driving in these conditions include monetary fines, detention and suspension of the driving license. In each road accident, if there are injuries or medical assistance is needed, the analyses of blood alcohol concentrations are required from the police officers [23].

The Laboratory of Forensic Toxicology of the Institute of Forensic Medicine in Tirana is the only one, authorized to perform the toxicological investigation of traffic accidents that happen all over the country (population 3.190.089).

The police officers usually request blood sampling of injured drivers or legal autopsy of deceased drivers, the blood samples are analyzed only for alcohol. The collection of urine is not a standard practice. This study aimed to investigate the presence of illegal drugs and psychoactive medicinal drugs among the crashed drivers in our country.

\section{Materials and Methods}

We considered 82 blood samples of crashed drivers from all country (selection criteria were applied), from January to December 2012, which were analyzed for both alcohol and drugs.

These cases represented only a portion of total accidents happened in that period (153 in total) which fulfill the selection criteria as following:

a. Drivers injured or killed in traffic accidents.

b. Time interval between the accident and sampling of less than 1 hour.

c. Sufficient blood available, to perform alcohol and drug analyses.

d. There were available data regarding: age of the person involved in accident, time of accident happened and time of blood sampling.

The rest of the blood samples from drivers involved in road accidents during that period, were analyzed for ethanol alone.

Blood sampling, was done shortly after the accident, venous blood was taken by a physician or nurse in the presence of police officer, using $5 \mathrm{cc}$ sterile tubes containing anticoagulants.

In fatal cases, heart blood samples were taken at autopsy, using

*Corresponding author: Vyshka G, Faculty of Medicine, University of Medicine Dibra Str. No.371, Tirana, Albania, Tel: +355 69 7566130; E-mail: gvyshka@gmail.com

Received June 21, 2016; Accepted July 23, 2016; Published August 02, 2016

Citation: Matua L, Xhemali B, Koçibelli M, Jucja B, Vyshka G (2016) Illicit Drugs among Crashed Drivers, A First Toxicological Investigation in Albania. Abnorm Behav Psychol 2: 120. doi: 10.4172/2472-0496.1000120

Copyright: ( 2016 Matua L, et al. This is an open-access article distributed under the terms of the Creative Commons Attribution License, which permits unrestricted use, distribution, and reproduction in any medium, provided the original author and source are credited. 
sterile plastic containers. Blood samples were stored at $+4^{\circ} \mathrm{C}$ till they were analyzed, normally within one week, and thereafter frozen at about $-20^{\circ} \mathrm{C}$ for a 3 month period.

Ethanol analysis was performed in $0.5 \mathrm{ml}$ of whole blood of the every sample was performed by a headspace gas chromatograph (Shimadzu) with a flame ionization detector using t-butanol as the internal standard, utilizing a GC head-space method [24]. One sample was measured twice and the mean value was reported. A sample was considered positive for alcohol when blood alcohol concentration was over $0.1 \mathrm{~g} / \mathrm{l}$.

In addition each blood sample was screened for the presence of drugs by an immunological method (AxSym Abbot). The cut-off levels of the first screening were: opiates $250 \mathrm{ng} / \mathrm{ml}$; cocaine metabolite $200 \mathrm{ng} /$ $\mathrm{ml}$; cannabinoids $20 \mathrm{ng} / \mathrm{ml}$; amphetamines $300 \mathrm{ng} / \mathrm{ml}$; benzodiazepines $250 \mathrm{ng} / \mathrm{ml}$, barbiturates $200 \mathrm{ng} / \mathrm{ml}$ and tricycle antidepressants $200 \mathrm{ng} /$ $\mathrm{ml}$. All positive screening results were confirmed by analyzing blood with gas-chromatography-mass-spectrometry (GC-MS by Shimadzu) using single ion monitoring, according to the standardized methods and procedures recommended in the "Manuals for use by National Laboratories by United Nations Drug Control Program" [25,26]. Statistical analyses were performed running the SPSS/PC program.

\section{Results}

A total of 153 persons injured or killed in road crashes in Albania during the year 2012 were submitted to Institute of Forensic Medicine for analyses of alcohol; the analytical results presented in this report are based only on 82 blood samples (54\%), which were analyzed for ethanol and drugs too. Drivers involved in accidents were more frequently men $98.8 \%(n=81) .46$ drivers $(56.1 \%)$ had a positive Blood Alcohol Concentration $(\mathrm{BAC} \geq 0.1 \mathrm{~g} / \mathrm{l})$ at the time of the crash, but only $23(28 \%)$ had toxic concentrations exceeding $1.2 \mathrm{~g} / \mathrm{l}$. Drivers with positive BAC were all men. It cannot be shown any significant increase of the BAC prevalence along decades of age, but it declines in ages over 60 years. Psychoactive substances, other than alcohol, were detected in 13 cases (15.9\%); in combination with alcohol in 5 cases (6\%); (benzodiazepines in 3 cases and MDMA in 2 cases). In total illicit drugs are found in $6 \%(n=5)$ respectively: cocaine $(n=1 ; 1.2 \%)$; methamphetamine $(n=1$; $1.2 \%)$, MDMA ( $\mathrm{n}=3 ; 2.4 \%)$; and regarding medicines the only one founded was diazepam, in $9.8 \%$ of crashed drivers $(n=8)$ (Table 1$)$.

We have not found any significant correlation between alcohol and/or drug positive cases and age, but we can notice that drugs are mostly used by 18 to 29 years old drivers.

The mean values of BAC for each age group were as follow: in under 29 years old drivers $0.49 \pm 0.61$; in 30 - 39 age group $0.68 \pm 0.76$; in 40-49 age group $1.19 \pm 1.19$; in $50-59$ age group $0.99 \pm 0.96$; in $60-69$ age group $0.48 \pm 0.73$ and in over $700.14 \pm 0.17$. We found the higher BAC mean value in 40-49 year old drivers. BAC mean value was higher during weekend $0.83 \pm 0.97$ compared to working days $0.67 \pm 0.92$. The highest $\mathrm{BAC}$ value was $3.344 \mathrm{~g} / \mathrm{l}$ in $40-49$ age groups.

The distribution of fatal cases in relation to time period of the week, age groups and blood alcohol concentration are presented in Table 2. (Night time from 18:00 to 5:59, weekend from Friday evening 18:00 to Monday morning 5:59).

\section{Discussion}

There has been an increase of road crashes and fatal cases during the five year period 2010- 2013 in Albania. Based in the Institute of Forensic Medicine database, sample distribution of fatal cases according to year was as follows: 2010,$60 ; 2011,46 ; 2012,71 ; 2013,91$. This was a modest study, based in a small number of cases but it was the first approach to analyze drugs in drivers involved in traffic accidents since it is not in the protocol of police officers to ask other than alcohol. Regarding to this study, alcohol was the most frequent (56.1\%) drug found and the highest blood alcohol concentration mean value was detected in 40-49 years old drivers. Our results are similar to those found in studies of alcohol in blood samples in other countries like Spain 44-50\%; USA 41-52\%, Canada 35-48\%, Norway 37.8\%, Greece 29-37\% [27-31]. Our findings show the presence of illegal drugs $(6 \%)$ and medicinal drugs (9.8\%) in drivers where combination of alcohol with drugs was found in $6 \%$ of cases, but further investigation and a bigger number of cases analyzed are needed to come to a conclusion. It is hard to compare with other countries findings because of the different study design and limited number of cases analyzed, but it is worth to notice that the most prevalent drug used was the benzodiazepines group (diazepam only). This is a similar finding to other European country [12]. We suppose using of diazepam is related to the easy way finding it and the low price. Regarding the age group of drivers consuming drugs, it is normal that young people dominate the picture (18-29 years old). Referring to European studies the most prevalent drug found in driver involved in road accidents is THC; but we can notice that cannabis is missing in our findings; maybe it is more popular and more used by teenagers group, which is not included in our study.

\section{Conclusion}

This study performed in 2012 revealed that beside alcohol, psychoactive substances are present in Albanian crashed drivers, too. The most commonly found illicit drug group was amphetamines, and the only group of medicinal drugs founded was the benzodiazepines. It shows that male drivers between 20 and 40 years are more likely to be involved in road accidents. Systematic future studies will help to estimate the drug use by drivers in our country. We recommend that a

\begin{tabular}{|c|c|c|c|c|c|c|c|c|c|c|c|c|}
\hline $\begin{array}{l}\text { Drivers } \\
\text { characteristics }\end{array}$ & $B A C=0$ & $\%$ & $0.1 \leq B A C<0.5$ & $\%$ & $0.5 \leq \mathrm{BAC}<1.2$ & $\%$ & $B A C \geq 1.2$ & $\%$ & Illicit Drugs & $\%$ & Medicinal & $\%$ \\
\hline \multicolumn{13}{|l|}{ Gender } \\
\hline Male & $35 / 81$ & 43.2 & Sep-81 & 11.1 & $14 / 81$ & 17.3 & $23 / 81$ & 28.4 & May-81 & 6.2 & Jul-81 & 8.6 \\
\hline Female & 1-Jan & 100 & 0 & 0 & 0 & 0 & 0 & 0 & 0 & 0 & Jan-81 & 1.2 \\
\hline \multicolumn{13}{|l|}{ Age } \\
\hline $18-29$ & 23-Nov & 47.8 & 23-Mar & 13 & 23-May & 21.8 & 23-Apr & 17.4 & 23-Mar & 13 & 23-Jun & 26.1 \\
\hline $30-39$ & 17-Jun & 35.4 & 17-Mar & 17.6 & 17-Apr & 23.5 & 17-Apr & 23.5 & 17-Feb & 11.8 & 17-Jan & 5.9 \\
\hline $40-49$ & 18-Jun & 33.3 & 18-Feb & 11.1 & 18-Feb & 11.1 & 18-Aug & 44.4 & 0 & 0 & 18-Jan & 5.6 \\
\hline $50-59$ & 12-May & 41.6 & $0 / 12$ & 0 & 12-Feb & 16.6 & 12-May & 41.6 & 0 & 0 & 0 & 0 \\
\hline $60-69$ & 9-Jun & 66.7 & $0 / 9$ & 0 & 9-Jan & 11.1 & 9-Feb & 22.2 & 0 & 0 & 0 & 0 \\
\hline$\geq 70$ & 3-Feb & 66.7 & 3-Jan & 33.3 & $0 / 3$ & 0 & $0 / 3$ & 0 & 0 & 0 & 0 & 0 \\
\hline
\end{tabular}

Table 1: Frequency of alcohol (BAC in $\mathrm{g} / \mathrm{l})$ and drug users in relation to gender and age groups. 
Citation: Matua L, Xhemali B, Koçibelli M, Jucja B, Vyshka G (2016) Illicit Drugs among Crashed Drivers, A First Toxicological Investigation in Albania Abnorm Behav Psychol 2: 120. doi: 10.4172/2472-0496.1000120

\begin{tabular}{|c|c|c|}
\hline & Nr. of fatal cases & $\%$ of total drivers \\
\hline \multicolumn{3}{|l|}{ Gender } \\
\hline Male & 48 & 58.5 \\
\hline Female & 0 & 0 \\
\hline \multicolumn{3}{|l|}{ BAC $g / l$} \\
\hline $\mathrm{BAC}=0$ & 22 & 26.8 \\
\hline $0.1 \leq \mathrm{BAC}<0.5$ & 7 & 8.5 \\
\hline $0.5 \leq \mathrm{BAC}<1.2$ & 6 & 7.3 \\
\hline$B A C \geq 1.2$ & 13 & 15.9 \\
\hline \multicolumn{3}{|l|}{ Drugs } \\
\hline Diazepam & 6 & 7.3 \\
\hline MDMA & 3 & 3.7 \\
\hline Methamphetamine & 1 & 1.2 \\
\hline \multicolumn{3}{|l|}{ Age } \\
\hline $18-29$ & 15 & 18.3 \\
\hline $30-39$ & 8 & 9.8 \\
\hline $40-49$ & 6 & 7.3 \\
\hline $50-59$ & 10 & 12.2 \\
\hline $60-69$ & 6 & 7.3 \\
\hline$\geq 70$ & 3 & 3.7 \\
\hline \multicolumn{3}{|l|}{ Weekday } \\
\hline working & 25 & 30.5 \\
\hline weekend & 23 & 28 \\
\hline \multicolumn{3}{|l|}{ Day/night } \\
\hline 06:00-17:59 & 27 & 32.9 \\
\hline 18:00-05:59 & 21 & 25.6 \\
\hline
\end{tabular}

Table 2: Distribution of fatal cases by blood alcohol concentration, age groups and time period.

drug check should be performed in persons involved in road accidents, further than alcohol analysis.

\section{References}

1. Phillips DP, Brewer KM (2011) The relationship between serious injury and blood alcohol concentration (BAC) in fatal motor vehicle accidents: $\mathrm{BAC}=0.01 \%$ is associated with significantly more dangerous accidents than $B A C=0.00 \%$. Addiction 106: 1614-1622.

2. Mets MA, Kuipers E, de Senerpont Domis LM, Leenders M, Olivier B, et al. (2011) Effects of alcohol on highway driving in the STISIM driving simulator. Hum Psychopharmacol 26: 434-439.

3. Allen AJ, Meda SA, Skudlarski P, Calhoun VD, Astur R, et al. (2009) Effects of alcohol on performance on a distraction task during simulated driving. Alcohol Clin Exp Res 33: 617-625.

4. Marczinski CA, Harrison EL, Fillmore MT (2008) Effects of alcohol on simulated driving and perceived driving impairment in binge drinkers. Alcohol Clin Exp Res 32: 1329-1337.

5. Mura P, Kintz P, Ludes B, Gaulier JM, Marquet P, et al. (2003) Comparison of the prevalence of alcohol, cannabis and other drugs between 900 injured drivers and 900 control subjects: results of a French collaborative study. Forensic Sci Int 133: 79-85.

6. Drummer $\mathrm{OH}$, Kourtis I, Beyer J, Tayler P, Boorman M, et al. (2012) The prevalence of drugs in injured drivers. Forensic Sci Int 215: 14-17.

7. Ronen A, Chassidim HS, Gershon P, Parmet Y, Rabinovich A, et al. (2010) The effect of alcohol, THC and their combination on perceived effects, willingness to drive and performance of driving and non-driving tasks. Accid Anal Prev 42 1855-1865.

8. Veldstra JL, Brookhuis KA, de Waard D, Molmans BH, Verstraete AG, et al. (2012) Effects of alcohol (BAC 0.5â€ $€^{\circ}$ and ecstasy (MDMA $100 \mathrm{mg}$ ) on simulated driving performance and traffic safety. Psychopharmacology (Berl) 222: 377-390.

9. Bosker WM, Kuypers KP, Conen S, Kauert GF, Toennes SW, et al. (2012) MDMA (ecstasy) effects on actual driving performance before and after sleep deprivation, as function of dose and concentration in blood and oral fluid. Psychopharmacology (Berl) 222: 367-376.
10. Vindenes V, Jordbru D, Knapskog AB, Kvan E, Mathisrud G, et al. (2012) Impairment based legislative limits for driving under the influence of nonalcohol drugs in Norway. Forensic Sci Int 219: 1-11.

11. Verster JC, Roth T (2013) Blood drug concentrations of benzodiazepines correlate poorly with actual driving impairment. Sleep Med Rev 17: 153-159.

12. Ferri M, Bo A (2013) EMCDDA best practice promotion in Europe: an internet based dissemination tool. Adicciones 25: 3-6.

13. Publication Office of the European Union (2012) Driving under the influence of Drugs, Alcohol and Medicines in Europe. European Monitoring Centre for Drugs and Drug Addiction.

14. de Carvalho Ponce J, Muñoz DR, Andreuccetti G, de Carvalho DG, Leyton V (2011) Alcohol-related traffic accidents with fatal outcomes in the city of Sao Paulo. Accid Anal Prev 43: 782-787.

15. Fabbri A, Marchesini G, Morselli-Labate AM (2002) Positive blood alcohol concentration and road accidents. A prospective study in an Italian emergency department. Emerg Med J 19: 210-214.

16. Holmgren P, Holmgren A, Ahlner J (2005) Alcohol and drugs in drivers fatally injured in traffic accidents in Sweden during the years 2000-2002. Forensic Sci Int 151: 11-17.

17. Jones AW, Kugelberg FC, Holmgren A, Ahlner J (2009) Five-year update on the occurrence of alcohol and other drugs in blood samples from drivers killed in road-traffic crashes in Sweden. Forensic Sci Int 186: 56-62.

18. AhIm K, Björnstig U, Oström M (2009) Alcohol and drugs in fatally and nonfatally injured motor vehicle drivers in northern Sweden. Accid Anal Prev 41: 129-136.

19. Costa N, Silva R, Mendonça MC, Real FC, Vieira DN, et al. (2012) Prevalence of ethanol and illicit drugs in road traffic accidents in the centre of Portugal: An eighteen-year update. Forensic Sci Int 216: 37-43

20. Fell JC, Voas RB (2006) The effectiveness of reducing illegal blood alcoho concentration (BAC) limits for driving: evidence for lowering the limit to 0.05 BAC. J Safety Res 37: 233-243.

21. Qirjako G, Burazeri G, Hysa B, Roshi E (2008) Factors associated with fatal traffic accidents in Tirana, Albania: cross-sectional study. Croat Med J 49: 734-740.

22. Matua L, Çinije M, Petrela E, Jucja B (2013) Alcohol in drivers fatally injured in road accidents in Albania during the years 2010-2012. European Sci Journal 9: $142-148$.

23. (2012) Road Code of Republic of Albania.

24. Kristoffersen L, Kielland AS (2006) Headspace gas chromatographic determination of ethanol: the use of factorial design to study effects of blood storage and headspace condition on ethanol stability and acetaldehyde formation in whole blood and plasma. Forensic Sci Int 161: 151-157.

25. Manual for Use by National Laboratories ST/NAR/28 (1997) Recommended methods for the detection and assay of barbiturates and benzodiazepines in biological specimens. United Nations.

26. Manual for Use by National Laboratories ST/NAR/27 (1995) Recommended methods for the detection and assay of heroin, cannabinoids, cocaine, amphetamine, methamphetamine, and ring-substituted amphetamine derivates in biological specimens. United Nations.

27. del Río MC, Gómez J, Sancho M, Alvarez FJ (2002) Alcohol, illicit drugs and medicinal drugs in fatally injured drivers in Spain between 1991 and 2000. Forensic Sci Int 127: 63-70.

28. Williams AF (2006) Alcohol-impaired driving and its consequences in the United States: the past 25 years. J Safety Res 37: 123-138.

29. Gjerde H, Christophersen AS, Normann PT, Mørland J (2011) Toxicological investigations of drivers killed in road traffic accidents in Norway during 2006 2008. Forensic Sci Int 212: 102-109.

30. Papadodima SA, Athanaselis SA, Stefanidou ME, Dona AA, Papoutsis I, et al. (2008) Driving under the influence in Greece: a 7-year survey (1998-2004) Forensic Sci Int 174: 157-160.

31. Dussault C, Brault M, Bouchard J, Lemire AM (2002) The contribution of alcoho and other drugs among fatally injured drivers in Quebec: some preliminary results. Proceedings of the 16th International Conference on Alcohol, Drugs and Traffic Safety. Societe de I'Assurance Automobile du Quebec, Montreal. pp: $423-430$ 